\title{
Game theoretic analysis of persons, the pharmaceutical industry, and donors in disease contraction and recovery
}

\author{
Kjell Hausken (1) ${ }^{1 凶} \&$ Mthuli Ncube ${ }^{2}$
}

Disease contraction and recovery depend on complex interaction between persons potentially contracting and recovering from the disease, the pharmaceutical industry potentially developing drugs, and donors potentially subsidizing drug development and drug purchases. Instead of analyzing each of these three kinds of players separately, assuming the behavior of the other two kinds of players to be given, this article analyzes the three kinds of players holistically and how they mutually interact and react to each other. A five-period game between $N$ persons and a pharmaceutical company is developed. Each person chooses safe or risky behavior, and whether or not to buy a drug. The objectives are to determine which strategies the $N$ persons and the pharmaceutical company choose depending on the model parameters. The pharmaceutical company develops the drug if sufficiently many persons contract the disease and buy the drug. A donor chooses parametrically whether to subsidize drug development and drug purchases. Nature chooses probabilistically disease contraction, and recovery versus death with and without applying the drug. The methodological procedure is to solve the game with backward induction specifying the conditions for each of five outcomes ranging from safe behavior to risky behavior and buying the drug. The results in the form of five outcomes for a person are safe behavior, risky behavior and no disease contraction, disease contraction without drug availability, disease contraction with drug availability but without buying the drug, and disease contraction and buying the drug. These five outcomes are spread across two outcomes for the pharmaceutical company which are not to develop versus to develop the drug. The utility for the donor is specified for these two outcomes. A procedure for estimating the parameters is presented based on HIV/AIDS data. The results are discussed in terms of how various parameter combinations cause the five outcomes. An example illustrates the players' strategic choices.

\footnotetext{
${ }^{1}$ Faculty of Science and Technology, University of Stavanger, 4036 Stavanger, Norway. ${ }^{2}$ Quantum Global Research Lab Ltd, Bahnhofstrasse 2, CH 6300 Zug, Switzerland. ${ }^{凶}$ email: kjell.hausken@uis.no
} 


\section{Introduction}

Background and contribution. Controlling known and unknown diseases is challenging. In 2019, 38 million people lived with HIV/AIDS. ${ }^{1}$ October 23, 2020, 42 million were infected with Covid-19, and one million had died. ${ }^{2}$ Empirical facts such as these justify analyzing the phenomenon which is global, and thus warrants international interest. Health policy decisions are usually analyzed non-game theoretically, as shown in the literature review below, which illustrates a gap in the literature. This article innovatively brings the relevant players together in a gametheoretic approach.

The article assesses the strategic choices of persons which engage in risky behavior which may cause disease. Each person chooses whether or not to buy a drug. A pharmaceutical company chooses whether or not to develop a drug to combat disease. A donor is introduced to choose parametrically whether to fund drug development for the pharmaceutical company and drug purchases for persons. Nature is introduced to determine three probabilities. The subject of study is thus potential disease contraction depending on persons' behavioral strategies, potential drug development by a pharmaceutical company if profit can be obtained, and recovery or death (or severely decreased life quality) for persons depending on how the game plays out.

A five-period game is developed between $N$ persons and a pharmaceutical company, which are assessed to be the most essential players to understand the phenomenon. Understanding the interaction between these players is believed to be societally beneficial. The choices of Nature and a donor are parametric. These players are also important, but Nature can hardly be assumed to maximize utility. A donor may sometimes maximize utility, and may sometimes be altruistic, e.g. when a government seeks to aid a community impacted by disease. A donor may sometimes not exist. This approach is novel and original and has not been conducted earlier.

In the five-period game, if the person chooses risky behavior, a disease such as a Covid-19 or HIV/AIDS virus attacks a person or not. The pharmaceutical company responds by developing or not developing a drug which the person buys or not. The donor may or may not subsidize drug development and drug purchases in varying degrees. Upon taking or not taking the drug, the person recovers or dies. Nature chooses disease contraction according to a given probability, and the disease recovery without and with the drug according to given probabilities.

The research methodology is to solve the game with backward induction starting with period 5 . In period 5 Nature chooses recovery versus death probabilistically. In period 4 a person buys the drug, sponsored by a donor, if the benefits outweigh the costs. In period 3 the pharmaceutical company develops the drug sponsored by a donor, if the benefits outweigh the costs. In period 2 Nature chooses disease contraction probabilistically. In period 1 the person chooses risky or safe behavior. The analysis gives five outcomes. The research questions are which strategies the $N$ persons and the pharmaceutical company choose, and which of the five outcomes arise depending on the model parameters.

The model helps understand individual behavior regarding contracting disease and the purchasing of drugs when interacting with a pharmaceutical company which may or may not develop a drug, a donor which may or may not subsidize, and Nature which may precariously determine disease contraction, recovery, and death. The integrated model brings together the relevant players in the decision-making process, all driven by incentives.

The model applies for a plethora of diseases satisfying three simple criteria. First, disease contraction depends on each person choosing risky as opposed to safe behavior, such as not wearing a mask against Covid-19 or not using a condom against HIV. That excludes e.g. genetically predisposed diseases and diseases striking randomly and independently of each person's behavior. Second, a pharmaceutical company is assumed which potentially may develop a drug against the disease. Although we refer to a pharmaceutical company, the model refers in principle to any player in any sector or market which may potentially develop a drug which may potentially cure a disease. If, hypothetically, a disease exists for which a drug cannot be expected, the general model simplifies to the special case where no drug is assumed available, which means that the person still has a choice between risky as opposed to safe behavior. Third, we confine attention to diseases where some kind of recovery is possible with or without a drug, and where the severity without recovery is above a certain level. Although that severity due to simplicity is described as death, a variety of milder degrees of severity can be envisioned, e.g. limitations in bodily or cognitive functions.

Given the empirically rich available data on HIV/AIDS, such data is used to illustrate the model. Empirical HIV/AIDS data is provided for prevalence, deaths, HIV expenditure, treatment costs, R\&D costs and revenues, and HIV resource availability. The data is used to provide a procedure for estimating the model parameters. An example illustrates outcomes that may follow from the players' strategic decisions. The model does not assume a certain study period, and applies for past and historic diseases, and future diseases. For the HIV/AIDS data used to illustrate the model, we use the most recently available data, and provide some data back to.

The pharmaceutical company may profit from drug development if sufficiently many persons buy the drug. The pharmaceutical company incurs costs of investing in drug research and development. The pharmaceutical company benefits if the patient takes the drug perpetually, like antiretroviral therapy (ART), or one off when the patient recovers completely. The person pays for the drug or it is donor-funded through aid flows. Persons contracting the disease may suffer consequences such as losing their jobs or otherwise experience decreased life quality.

Doctors, hospitals, and other players (aside from donors) in the national and international health system and political system are not explicitly present in the model as players since we focus on the strategic interaction between $N$ persons and the pharmaceutical company, parametrically impacted by a donor and Nature. Various other players play a key role by advising patients on risky versus safe behavior, advising on whether or not to buy the drug, aiding in consuming the drug, advising the pharmaceutical about the characteristics of the disease and other factors relevant for drug development, etc. These other aspects are important, but the essentials are that the $N$ persons choose risky or safe behavior, and the pharmaceutical company chooses whether or not to develop the drug.

\section{The literature}

Game-theoretic studies. To position the article within the literature, let us consider some related contributions and previous work that to some extent has considered some parts of the phenomenon. Game-theoretic contributions are uncommon for this phenomenon. Hausken and Ncube $(2017,2018)$ consider the interaction between policy makers choosing resource allocation between prevention and treatment of disease, the international community choosing funding to treat disease, and Nature choosing which fraction of the population contracts disease, and which fractions remains sick or dies, versus recovers. They find that more resource allocation to disease prevention rather than treatment causes less disease contraction but higher death rate given disease contraction. They also assess how a policy maker and the international community may free ride on each other's 
resource contributions. That contrasts with the objective of this article where a pharmaceutical company assesses whether or not to develop a drug for disease treatment. The focus on disease prevention is indirect in this article since potential drug availability and cost impacts a person's choice of risky versus safe behavior indirectly, where safe behavior may prevent disease contraction.

Mamani et al. (2013) present a game-theoretic model of international influenza vaccination coordination. They propose a contractual mechanism to remedy the inefficient allocation of influenza vaccines within multiple countries impacted by the interdependent risk of infection across borders. Their mechanism is shown to decrease the global financial burden of infection and decrease the total number of infected persons, especially with high cross-border transmission rates. Whereas their gametheoretic model assumes that the vaccine is available and needs to be distributed, this article assumes that the drug is initially unavailable and needs to be developed.

\section{Non-game theoretic studies}

Treatment. The model in this article assumes that a drug may be developed to cure a disease which may be contracted. A similar focus on treatment rather than prevention is strong in the literature, which is largely non-game theoretic. Kremer and Snyder (2003, 2015), Thomas (2001), and Kremer and Glennerster (2004) find that incentives for developing drugs for treatment seem far stronger than incentives for developing vaccines for prevention. This may cause more citizens to become sick and force high disease prevalence countries to allocate more resources to treatment than prevention.

Regarding treatment, Forsythe et al. (2019) consider the global costs, health achievements, and economic benefits of 20 years of ART for people living with HIV. They document substantial improvement, which this article may also facilitate if drug development proves possible, which in turn depends on the game with persons potentially buying drugs, and donors sponsoring drug development and purchases. DiMasi et al. (2016) estimate $\$ 2.6$ billion for HIV drug R\&D costs for the years 2017-2021, which usefully may illustrate what kind of progress can be expected. West and Schneider (2018) estimate revenues for HIV/AIDS treatment for the years 2017-2021 for various African countries, which is similarly useful. Hecht et al. (2010) and Izazola-Licea et al. (2009) assess the financing of the response to HIV/AIDS in low-income and middle-income countries. Goldie et al. (2006) evaluate the cost-effectiveness of HIV treatment in resource-poor settings. They recommend trimethoprim-sulfamethoxazole prophylaxis and ART, applying clinical criteria alone or in combination with $\mathrm{CD} 4$ testing to guide the timing of treatment.

Prevention and treatment. A variety of studies focus on both prevention and treatment. Alistar and Brandeau (2012) summarize modeling approaches and seek to identify characteristics in a model to support and scale-up decision making about HIV prevention and treatment. Their focus on flexibility to enable parameter customization and incorporation of uncertainty is similar to the focus on different values for the parameters in this article's model which determines which of multiple outcomes occurs.

Bärnighausen et al. (2012) evaluate HIV treatment as prevention (TasP) programs economically. They argue that ART outcomes and costs in current TasP programs are unlikely to generalize to other TasP programs due to various changes, and that less detailed cost functions may be sufficient. That again illustrates the need for flexible models enabling variation in parameter values.

Also focusing on TasP, Boily et al. (2012) assess the design, conduct, and analysis of cluster randomized controlled trials. They find that even with combination interventions, decreasing the HIV incidence over 2-3 years of intervention is challenging, unless interventions are scaled up to reach key populations, for which they propose mathematical modeling to conduct interim analyses. Such a focus in intervention is not explicit in this article's model, though the drug availability combined with pricing and marketing may implicitly raise the awareness of person's choosing risky versus safe behavior.

Granich et al. (2012) consider the cost effectiveness of HIV prevention and treatment. They find that increasing the provision of ART to $<350$ cells $/ \mathrm{mm}^{3}$ may significantly reduce costs while reducing the HIV burden. They further estimate cost and costeffectiveness for the period 2011-2050. Hogan et al. (2005) evaluate the costs and health effects of interventions for HIV prevention and treatment. With scarce resources they recommend mass media campaigns, interventions for sex workers, and treatment of sexually transmitted infections. With more available resources they recommend prevention of mother to child transmission, voluntary counseling and testing, and schoolbased education. For further studies on prevention and treatment, see Bertozzi et al. (2006), Gonsalves (2002), and Kumaranayake et al. (2001).

Moxnes and Hausken (2012) model with differential time equations the immune system and the virus dynamics of acute virus influenza $\mathrm{A}$ infections, showing good agreement with the evolution of the 1918 Spanish flu virus H1N1. Their non-game theoretic analysis is relevant for drug development of both vaccines for prevention and drugs for treatment, which in turn impacts the game between the pharmaceutical company and persons analyzed in this article.

Prevention. Some studies focus more explicitly on prevention. The HIV Modeling Consortium TasP Editorial Writing Group (2012) argue that epidemiology, economics, demography, statistics, biology, and mathematical modeling are essential to determine the optimal use of ART. The group recommends collaboration between disciplines to support evidence-based decision making in HIV prevention.

Coates et al. (2008) analyze behavioral strategies to reduce HIV transmission. They argue that decreasing HIV transmission requires radical and sustained behavioral changes, that combination prevention is essential through a mix of communication channels, that prevention programs and prevention science can do better, and that HIV prevention methods need to be agreed upon, funded, implemented, measured, and achieved. This article incorporates game theory into some of these considerations by assessing how drug development, donor subsidies, and probabilities of disease contraction, recovery, and death impact persons' behavioral strategies interpreted as risky versus safe behavior.

Galárraga et al. (2009) suggest that lack of convincing evidence of cost-effectiveness may explain why implementation of effective programs are not implemented at sufficient scale, and why over 7000 people become HIV infected per day. They assess various studies focusing on the cost effectiveness in terms of cost per HIV infection averted, cost per disability-adjusted life year, and quality-adjusted life year. The conclude that the sparse cost effectiveness evidence is not easily comparable, and thus not very useful for decision making to prevent infection. For further studies of the cost effectiveness of intervention to prevent HIV infection, see Canning (2006), Cohen et al. (2005), Walker (2003), Creese et al. (2002), and Paltiel and Stinnett (1998). 


\section{Table 1 A literature review table.}

\section{Reference}

Hausken and Ncube (2017, 2018)

Mamani et al. (2013)

Kremer and Snyder (2003, 2015), Thomas (2001), and Kremer T and Glennerster (2004)

Forsythe et al. (2019)

DiMasi et al. (2016)

West and Schneider (2018)

Hecht et al. (2010), Izazola-Licea et al. (2009)

Goldie et al. (2006)

Alistar and Brandeau (2012)

Bärnighausen et al. (2012)

Boily et al. (2012)

Granich et al. (2012)

Hogan et al. (2005)

Bertozzi et al. (2006), Gonsalves (2002), and Kumaranayake et al. (2001)

Moxnes and Hausken (2012)

HIV modeling consortium treatment as Prevention Editorial

Writing Group (2012)

Coates et al. (2008)

Galárraga et al. (2009)

Canning (2006), Cohen et al. (2005), Walker (2003), Creese

et al. (2002), and Paltiel and Stinnett (1998)

Fitzpatrick et al. (2017)

\section{Study Characteristics}

G

G

$\mathrm{T}$

$\mathrm{T}$

$\mathrm{T}$

$\mathrm{T}$

$\mathrm{T}$

$\mathrm{T}$

PT

PT

PT

PT

PT

PT

PT

P

$P$

$P$

$\mathrm{P}$

Policy makers, the international community, and Nature choosing disease contraction and recovery

International influenza vaccination coordination

Incentives for developing drugs for treatment seem stronger than incentives for developing vaccines for prevention

Global costs, health achievements, and economic benefits of twenty years of ART

Estimation of $\$ 2.6$ billion for HIV drug R\&D costs during 2017-2021

Revenues for HIV/AIDS treatment during 2017-2021 for some African countries

Financing of the response to HIV/AIDS in low-income and middle-income countries

Cost-effectiveness of HIV treatment in resource-poor settings

Summarize modeling approaches. Identify characteristics to scale-up decision making about HIV prevention and treatment

Evaluate HIV treatment as prevention (TasP) programs economically

Assess design, conduct, and analysis of cluster randomized controlled trials of TasP

Cost effectiveness of HIV prevention and treatment

treatment

Assessment of prevention and treatment

$\mathrm{G}$ means game theoretic study. T means non-game theoretic study involving treatment. PT means non-game theoretic study involving prevention and treatment. P means non-game theoretic study involving prevention.

Finally, and more generally, Fitzpatrick et al. (2017) recommend a Congressional cost-effectiveness committee to promote societal welfare and reveal underinvestment in public health compared with other sectors.

A literature review table. Table 1 provides a table summarizing the literature review to identify research gaps.

Article organization. Section "The model" presents the model. Section "Analyzing the model" analyzes the model. Section "HIV treatment costs and R\&D costs and revenues" considers HIV treatment costs and R\&D costs and revenues. Section "A procedure for estimating the model parameters, with exemplification" suggests a procedure for estimating the model parameters and linking the data to the model, with exemplification. Section "Discussion of results, limitations and future research" concludes.

\section{The model}

\section{Nomenclature.}

Parameters

$N$ number of persons

$G$ number of persons choosing safe behavior

$L$ number of persons choosing risky behavior while not contracting the disease

$m$ number of persons buying drug

$M$ number of persons not buying drug despite drug production by pharmaceutical company
$C$ drug purchasing cost for person $i, i=1, \ldots, N$

$c$ drug production cost for the pharmaceutical company destined for person $i, i=1, \ldots, N$

$k$ exponential parameter scaling drug production cost

$d$ drug development cost

$E_{i}$ person $i$ 's utility of risky behavior, $\mathrm{i}=1, \ldots, N$

$H_{i}$ person $i$ 's utility of safe behavior, $H_{i}<E_{i}, i=1, \ldots, N$

$R_{i}$ person $i$ 's utility when recovering from disease, $R_{i}<H_{i}, i=1$, $\ldots, N$

$D_{i}$ person $i$ 's utility of death, $D_{i}<R_{i}, i=1, \ldots, N$

Strategic choices by person $i, i=1, \ldots, N$

Choice between risky behavior and safe behavior, in period 1

Choice whether to buy drug or not buy drug, in period 4

Strategic choice by pharmaceutical company

Choice whether to develop drug, in period 3

Strategic choices by donor

$X$ Subsidy fraction of drug development cost $d$ in period 3, $0 \leq$ $X \leq 1$

$S$ Subsidy fraction of drug purchasing cost $C$ for person $i$ in period $4,0 \leq S \leq 1$

Strategic choices by Nature

$q$ disease contraction probability in period $2,0 \leq q \leq 1$

$x$ disease recovery probability without drug in periods 4 and/or $5,0 \leq x \leq 1$

$w$ disease recovery probability with drug in period $5,0 \leq x \leq$ $w \leq 1$

Dependent variables

$p$ fraction of the $N$ persons choosing risky behavior, $0 \leq p \leq 1$ 


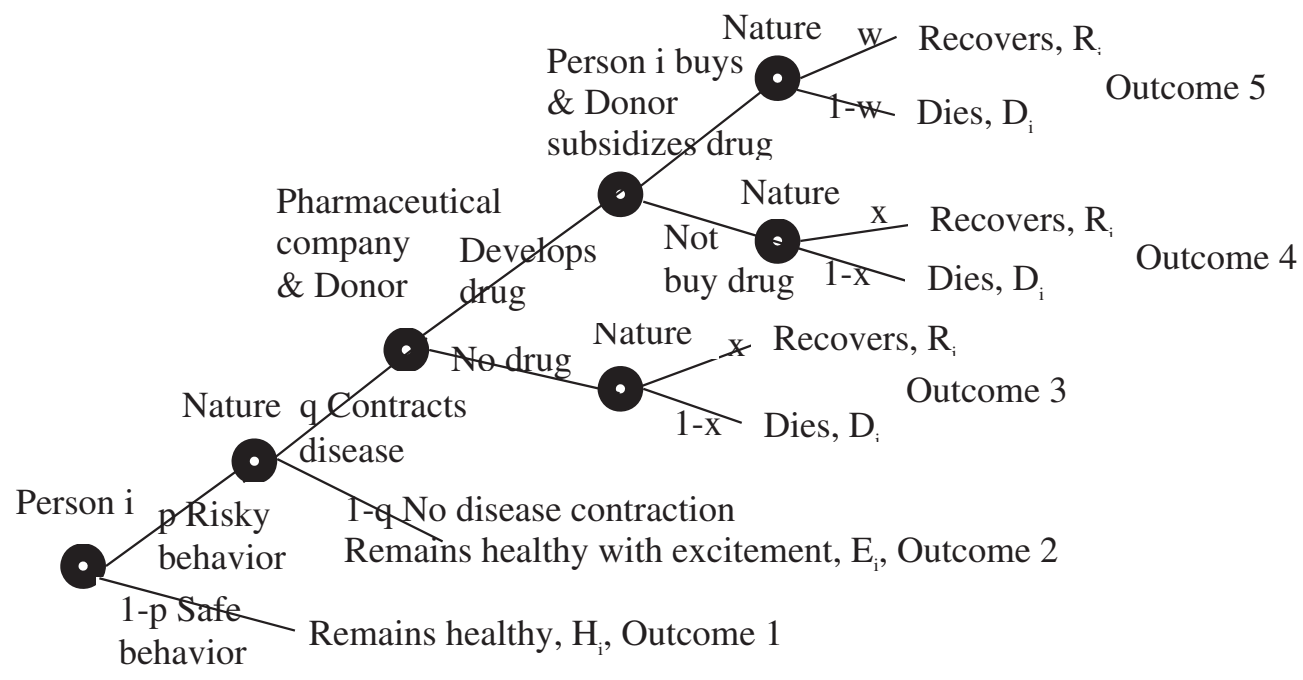

\section{Period $1 \quad$ Period 2 Period $3 \quad$ Period $4 \quad$ Period 5}

Fig. 1 Five-period game between person $i$, the pharmaceutical company, the donor, and Nature. Please see the article text for figure description and the nomenclature in the beginning of this section for a description of the symbols used.

$U_{i}$ person $i$ 's utility, $i=1, \ldots, N$

$u$ pharmaceutical company's profit

$V$ donor's utility

The model. A population of $N$ persons is considered together with the complete information five-period game in Fig. 1 between person $i, i=1, \ldots, N$, the pharmaceutical company, the donor, and Nature. In period 1 person $i$ chooses risky versus safe behavior. In period 2 Nature chooses whether the disease is contracted. In period 3 the pharmaceutical company chooses whether to develop a drug. In period 4, with no drug, Nature chooses recovery versus death. In period 4 , with drug development, person $i$ chooses whether or not to buy it, potentially subsidized by a donor. In period 5, Nature chooses recovery versus death.

More specifically, the game has seven choice (decision) nodes. Person $i$ chooses in period 1 whether to engage in risky behavior with positive utility $E_{i}$ if not contracting the disease, or safe behavior with positive utility $H_{i}<E_{i}$ which means remaining healthy. A fraction $p$, determined as a consequence of the $N$ persons' choices, and hence $p N$ persons, chooses risky behavior. Person $i$ 's risky behavior in period 1 may involve consistently risky choices over several months or years, such as not wearing a mask against Covid-19 or not using a condom against HIV. Risky behavior causes disease contraction chosen by Nature with probability $q$ in period 2 . Hence $p q N$ persons contract the disease.

The pharmaceutical company chooses in period 3 either to develop the drug at cost $d$ subsidized by a donor with a fraction $X$, $0 \leq X \leq 1$, or not to develop the drug at no cost. Thus the pharmaceutical company pays $(1-X) d$ for drug development. Design, development and approval of a drug for use in patients can take 10-15 years, which can sometimes be expedited, e.g. if the drug is the first available treatment for a disease, or is estimated to provide significant benefit over existing drugs (Lansdowne, 2020). Even compared with expedited drug approval processes, the cycle time of many or most diseases is lower or significantly lower. Thus persons choosing risky behavior in period 1 and contracting the disease in period 2, before the pharmaceutical company has started drug production, may face the possibility of no drug availability in period 3. From the person's perspective, this is technically interpreted so that the pharmaceutical company chooses not to develop the drug. A person may thus have to live with the disease for a substantial amount of time before the drug becomes available, or may die before the drug becomes available. Since the pharmaceutical company's decision process may take 10-15 years, and a person can not buy a drug before it has been approved and is available, from the person's perspective we can consider the point in time after 10-15 years as the decision making time of the pharmaceutical company in period 3. Before 10-15 years have elapsed, uncertainty exists whether a drug will be available. This means that even though in practice the pharmaceutical company may have started the 10-15 years process of design, development and approval of a drug, persons make choices of risky versus safe behavior in period 1 without knowing the pharmaceutical company's choice in period 3 which does not become available until the drug becomes approved or not approved after 10-15 years.

With no drug for person $i$, Nature chooses in period 4 recovery with probability $x$ and positive utility $R_{i}<H_{i}$, or death with probability $1-x$ and negative utility $D_{i}<R_{i}$, and the game ends. Death may alternatively be interpreted as severely decreased life quality. If the drug is developed, person $i$ chooses in period 4 either to buy it at cost $C$ subsidized by the donor with a fraction $S$, $0 \leq S \leq 1$, or not to buy it. The donor may consist of multiple donors considered as one collective unit. If person $i$ buys the drug, paying $(1-S) C$, in period 5 Nature chooses recovery or death with probabilities $w$ and $1-w$, respectively. If person $i$ does not buy the drug, in period 5 Nature chooses recovery or death with probabilities $x$ and $1-x$, respectively. The probabilities $p, q, x$, $w$ are independent between nodes and individuals.

Summing up, person $i$ has two strategic choice variables. It chooses risky or safe behavior in period 1, and chooses whether or not to buy the drug in period 4 (if the pharmaceutical company has developed it in period 3). The pharmaceutical company has one strategic choice variable, i.e. whether or not to develop the drug in period 3. The donor has two strategic choice variables. It chooses the subsidy fraction $X$ to pay for drug development in period 3, and the subsidy fraction $S$ to pay for each person $i$ 's drug purchase in period 4 . Nature has three strategic choice variables in four choice nodes. It chooses the disease contraction probability $q$ in period 2, the recovery probability $x$ in period 4 if no drug is developed, the same recovery probability $x$ in period 5 if the drug is developed but not bought (and thus not applied), and the recovery probability 
Table 2 Outcomes, number of persons choosing the various strategies, and the pharmaceutical company's drug development strategy.

\begin{tabular}{|c|c|c|c|c|c|}
\hline Outcome & 1 & 2 & 3 & 4 & 5 \\
\hline Number of persons & $G$ & $L$ & $N-G-L-M-m$ & $M$ & $m$ \\
\hline Person $i$ & Safe behavior & Risky behavior & Disease contraction & Not buy drug & Buy drug \\
\hline$m$ & 0 & 0 & 0 & 0 & $>0$ \\
\hline Company's profit & 0 & 0 & 0 & $-(1-X) d$ & Eq. (2) \\
\hline Company & \multicolumn{3}{|c|}{ No drug development } & Drug developn & \\
\hline
\end{tabular}

$w$ in period 5 if the drug is bought (and applied), where $0 \leq x \leq$ $w \leq 1$.

Tractability is ensured by all $N$ persons starting the game simultaneously and proceeding at the same pace through the five periods. Each person $i$ has different preferences for safe versus risky behavior due to assigning different utilities to remaining healthy without or with excitement, to death, and to recovery. The game may end after each period, and generally ends in different periods for each person $i$ depending on the different strategic choices.

Individual persons' behavior, benefits, and costs. Figure 1 has five outcomes when not counting Nature's probabilistic choice of recovery or death. Counting these five outcomes from the root in the game tree and outwards through the branches, and listing them from condition 1 through condition 5 , person $i$ 's utility is

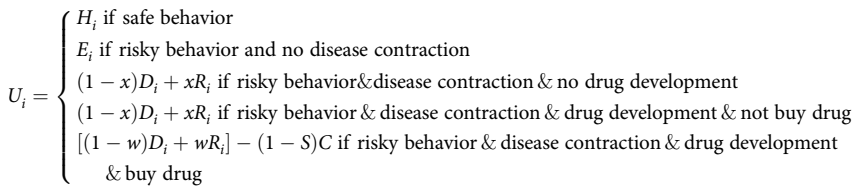

Condition 1 applies for a risk averse person $i$ assigning high utility $H_{i}$ to safe behavior and low utility to the outcomes of risky behavior when assessing the probabilities, drug production and costs. Condition 2 applies when Nature chooses no disease contraction, which gives utility $E_{i}>H_{i}$. Conditions 3 and 4 in Eq. (1) are equivalent since if person $i$ does not buy the drug, then it is irrelevant whether the drug is developed or not. Condition 5 states that person $i$ buys the drug at cost $(1-S) C$.

With no drug development, only the first three outcomes in Eq. (1) are possible. The third outcome gives death with probability $1-x$ and recovery with probability $x$. Consequently all four utilities $H_{i}, E_{i}, D_{i}, R_{i}$ are possible. If the pharmaceutical company develops the drug, all the five outcomes are possible. The $N$ persons have different $H_{i}, E_{i}, D_{i}, R_{i}$, and distribute themselves across the three or five outcomes, depending on whether the drug is not developed, or developed.

Pharmaceutical company's behavior, benefits, and costs. The pharmaceutical company's profit depends on the numbers of persons buying the drug, the drug price, and the costs of drug development. We assume that $m$ persons buy the drug, which allows outcome 5. This assumption is in accordance with Fig. 1 where persons are not allowed to enter the game in later periods. The pharmaceutical company's profit is

$$
u=\left\{\begin{array}{l}
0 \text { if no drug development } \\
m C-(m c)^{k}-(1-X) d \text { if drug development }
\end{array}\right.
$$

where $c$ is the drug production cost for the pharmaceutical company in the amount required for person $\mathrm{i}, i=1, \ldots, N$, and $k$ scales the production cost. In Eq. (2), the positive term $m C$ expresses the pharmaceutical company's profit from selling the drug at the price $C$ to $m$ buyers. The negative term $(m c)^{k}$ is the pharmaceutical company's cost of producing the drug for $m$ buyers. The negative term $(1-X) d$ is the pharmaceutical company's drug development cost adjusted by the donor subsidy fraction $X$. When $k=1$, production cost is linear. When $0<k<1$, production cost is concave (economy of scale). When $k>1$, production cost is convex (diseconomy of scale). Condition 1 in line 1 in Eq. (2) corresponds to $m=0$ where the $N$ persons distribute themselves across outcomes 1-3, and condition 2 in line 2 in Eq. (2) corresponds to $m \geq 0$ where the $N$ persons distribute themselves across all the five outcomes 1-5. For the pharmaceutical company to develop the drug in period 3, at least one person must contract the disease and then that person can choose whether or not to buy the drug.

Table 2 lists the five outcomes in the first row, and the number of persons choosing each outcome in row 2, where $G$ (for being guarded) is the number of persons choosing safe behavior and $L$ (for lucky) is the number of persons choosing risky behavior while not contracting the disease. We define $M$ as the number of persons not buying the drug despite drug production by the pharmaceutical company. With these definitions, $N-G-L-M-m$ is the unfortunate number of persons with outcome 3 contracting the disease without drug availability. Row 3 lists person $i$ 's strategy. The pharmaceutical company is interested in row 4 which shows the number $m$ of persons buying the drug. Row 5 shows that the pharmaceutical company earns zero or negative profit for outcomes $1-4$, and may earn positive profit for outcome 5 . The bottom row 6 shows the pharmaceutical company's drug development strategy.

In outcomes 1-3 the pharmaceutical company does not develop the drug, due to no profits from doing so. Only in outcomes 4 and 5 does the pharmaceutical company make profits and therefore develop the drug.

Donor's behavior, benefits, and costs. The donor's benefit is the sum of the $N$ persons' benefits $H_{i}, E_{i}, D_{i}, R_{i}$ accounting for Nature's probabilities $q, x, w$, the donor's choices of $X$ and $S$, and number of persons choosing the five outcomes. The donor incurs a cost $X d$ of subsidizing drug development, and incurs a cost SC of subsidizing person $i$ 's drug purchasing cost, i.e. $m S C$ for the $m$ persons purchasing the drug. The subsidies $S$ and $X$ are assumed to be parametric and hence we do not consider the strategic choices of the donor. For the donor's utility we get the same two conditions as for the pharmaceutical company's profit in Eq. (2), i.e.

$$
V=\left\{\begin{array}{l}
\sum_{i=1}^{G} H_{i}+\sum_{i=G+1}^{G+L} E_{i}+\sum_{i=G+L+1}^{N-M-m}\left[(1-x) D_{i}+x R_{i}\right] \\
\text { and } M=m=0 \text { if no drug development } \\
\sum_{i=1}^{G} H_{i}+\sum_{i=G+1}^{G+L} E_{i}+\sum_{i=G+L+1}^{N-M-m}\left[(1-x) D_{i}+x R_{i}\right] \\
\quad+\sum_{i=N-M-m+1}^{N-m}\left[(1-x) D_{i}+x R_{i}\right] \\
\quad+\sum_{i=N-M+1}^{N}\left(\left[(1-w) D_{i}+w R_{i}\right]-S C\right)-X d \text { if drug development }
\end{array}\right.
$$

Condition 1 in line 1 in Eq. (3) covers outcomes 1-3 with no subsidies. The $N$ persons distribute themselves across outcomes 
Table 3 The five outcomes 0 , the description, the equations that apply, the conditions, and an example (section "A procedure for estimating the model parameters, with exemplification").

\begin{tabular}{|c|c|c|c|c|}
\hline $\mathbf{0}$ & Description & Equations & Conditions & Example \\
\hline 1 & Person $i$ prefers safe behavior & $\begin{array}{l}\text { Neither Eq. (6) nor Eq. (7) are } \\
\text { satisfied }\end{array}$ & $\begin{array}{l}(1-q) E_{i}+q\left((1-x) D_{i}+x R_{i}\right)<H_{i} \\
(1-q) E_{i}+q\left((1-w) D_{i}+w R_{i}-(1\right. \\
-S) C)<H_{i}\end{array}$ & $\begin{array}{l}272,000<500,000 \text { Yes } \\
847,995>500,000 \text { No }\end{array}$ \\
\hline 3 & Contracting disease without drug availability & $\begin{array}{l}\text { Eqs. (4) and (5) are not satisfied, and } \\
\text { Eq. (6) is satisfied }\end{array}$ & $\begin{array}{l}(w-x)\left(R_{i}-D_{i}\right)<(1-S) C \\
m C-(m c)^{k}<(1-X) d \\
(1-q) E_{i}+q\left((1-x) D_{i}+x R_{i}\right) \geq H_{i}\end{array}$ & $\begin{array}{l}5.76 \times 10^{6}>50 \text { No } \\
1.4 \times 10^{9}>1.3 \times 10^{9} \text { No } \\
272,000<500,000 \text { No }\end{array}$ \\
\hline 4 & $\begin{array}{l}\text { Contracting disease with drug availability, but } \\
\text { without buying drug }\end{array}$ & $\begin{array}{l}\text { Eq. (4) is not satisfied, Eqs. (5) and } \\
(6) \text { are satisfied }\end{array}$ & $\begin{array}{l}(w-x)\left(R_{i}-D_{i}\right)<(1-S) C \\
m C-(m c)^{k} \geq(1-X) d \\
(1-q) E_{i}+q\left((1-x) D_{i}+x R_{i}\right) \geq H_{i}\end{array}$ & $\begin{array}{l}5.76 \times 10^{6}>50 \text { No } \\
1.4 \times 10^{9} \geq 1.3 \times 10^{9} \text { Yes } \\
272,000<500,000 \text { No }\end{array}$ \\
\hline 5 & $\begin{array}{l}\text { Contracting disease with drug availability and } \\
\text { buying drug }\end{array}$ & Eqs. (4), (5), (7) are satisfied & $\begin{array}{l}(w-x)\left(R_{i}-D_{i}\right) \geq(1-S) C \\
m C-(m c)^{k} \geq(1-X) d \\
(1-q) E_{i}+q\left((1-w) D_{i}+w R_{i}-(1\right. \\
-S) C) \geq H_{i}\end{array}$ & $\begin{array}{l}5.76 \times 10^{6} \geq 50 \text { Yes } \\
1.4 \times 10^{9} \geq 1.3 \times 10^{9} \text { Yes } \\
847,995>500,000 \text { Yes }\end{array}$ \\
\hline
\end{tabular}

Yes and No in the rightmost column express whether each example inequality matches the corresponding condition in the second column from the right

$1-3$. Hence $(1-x) D_{i}+x R_{i}$ in the third sum is summed from $G+L+1$ to $N$. Condition 2 in lines 2 and 3 in Eq. (3) $c$ overs outcomes $1-5$ with subsidies $m S C$ and $X d$. Hence $(1-x) D_{i}+x R_{i}$ in the third sum is summed from $G+L+1$ to $N-M-m$. The fourth and fifth sums are over $M$ and $m$ persons, respectively.

\section{Analyzing the model}

The game is solved with backward induction starting with period 5. Nature's three strategies are probabilistic with the probabilities $q, x, w$ in Fig. 1. In period 5 Nature chooses recovery from the disease according to the probabilities $w$ and $x$, when the drug has been applied and not applied, respectively. If the drug has not been developed, $x$ is determined in period 4 . In period 4 person $i$ buys the drug if the benefits outweigh those of not buying the drug, that is

$$
\begin{aligned}
& \left((1-w) D_{i}+w R_{i}\right)-(1-S) C \geq(1-x) D_{i}+x R_{i} \\
& \Rightarrow(w-x)\left(R_{i}-D_{i}\right) \geq(1-S) C .
\end{aligned}
$$

If Eq. (4) is not satisfied for $m$ persons, the pharmaceutical company does not develop the drug. Otherwise in period 3 the pharmaceutical company develops the drug, sponsored by a donor, if it is profitable, that is

$$
m C-(m c)^{k}-(1-X) d \geq 0 \Rightarrow m C-(m c)^{k} \geq(1-X) d .
$$

In period 2 Nature chooses disease contraction given risky behavior according to the given probability $q$. In period 1 person $i$ chooses risky or safe behavior. If the drug is not optimal for person $i$ to buy, it chooses risky behavior if

$$
(1-q) E_{i}+q\left((1-x) D_{i}+x R_{i}\right) \geq H_{i} .
$$

If the drug is optimal for person $i$ to buy, it chooses risky behavior if

$$
(1-q) E_{i}+q\left((1-w) D_{i}+w R_{i}-(1-S) C\right) \geq H_{i} .
$$

No disease contraction, which corresponds to inserting $q=0$ into Eq. (6) or Eq. (7), gives

$$
E_{i} \geq H_{i}
$$

which is satisfied by assumption guaranteeing risky behavior. Table 3 lists the five outcomes $\mathrm{O}$, which are the five lines in Eq. (1), in the left column, description in column 2, lists the equations that apply in column 3 , lists the conditions in column 4 , and presents an example (considered later in the article) in the right column.

\section{HIV treatment costs and R\&D costs and revenues}

Costs of HIV/AIDS treatment. Affordability remains a critical issue, despite the fact that between 2000 and 2007, the median price for first-line combination therapy in developing countries fell from $\$ 10,000$ to below $\$ 100$ per patient per year, which still is approximately the price today (Médecins Sans Frontières, 2020). In 2017 the Clinton Health Access Initiative (2018) and partners announced an agreement to enable the availability of the first affordable, generic, single-pill HIV treatment containing dolutegravir (DTG) to public sector purchasers in low-income and middle-income countries to around $\$ 75$ per person, per year. Somewhat differently, Pillai et al. (2019) find that the mean yearly cost of pre-ART HIV care is $\$ 158.52$, i.e., more specifically, $\$ 379.32$, \$153.36, \$151.80, \$143.16 for those with CD4 count $<100,101-350,351-500$, and $>500$ cells $/ \mathrm{mm}^{3}$, respectively.

Even \$75-160 remains unaffordable for many low-income countries, even when considering the growing availability of donor funds. In addition, an increasing number of "People Living With HIV/AIDS" require second-line treatment because of resistance to first-line drug treatment or an inability to tolerate first-line drugs. As a result, many low- and middle-income countries are struggling to provide sustainable access to HAART (abacavir + didanosine + lopinavir/ritonavir) which includes both first and second-line therapies.

In 2007, the World Health Organization (2020) reported that the median price for the most frequently used second-line HAART for low-income countries was $\$ 1214$, i.e. around 12 times as high as for the first-line treatment, which has been relatively stable during 2007-2020. The World Health Organization (2020) reports that for 2008, in middle-income countries, the price for second-line therapy was 36.3 times higher than for firstline therapy ( $\$ 3,306$ for second-line therapy, as compared to $\$ 91$ for first-line therapy). Similarly, Médecins Sans Frontières (2020) reports that according to manufacturer price information, a change from the cheapest first-line regime quoted with $\$ 87$ to the cheapest second-line with $\$ 749$ (tenofovir + emtricitabine + lopinavir/ritonavir) will increase expenditures at least ninefold.

Which factors impact prices? Several publications have described factors that may impact drug prices in general. It is understood that bulk procurement (large volume) results in price 
reduction (World Health Organization, 2020). Many pharmaceutical manufacturers, particularly innovators of ARV such as Merck, GlaxoSmithKline, Bristol Myers Squibb, state that they are using price tiers depending on the countries' socioeconomic status. Some base their classification on the World Bank definition of low, lower-middle, upper-middle, and high-income countries (World Bank, 2019). Other companies have used their own classification (Médecins Sans Frontières, 2020). Another factor influencing prices is using particular procurement processes such as third party negotiation. For instance, the Clinton Health Access Initiative (2018) negotiates procurement prices on behalf of its member countries with mainly generic manufacturers.

HIV R\&D costs and revenues. DiMasi et al. (2016) estimate \$2.6 billion for HIV drug R\&D costs for the years 2017-2021. They assess a corporate tax rate of $30 \%$ with limited deductions based on numbers from African countries, and a $12 \%$ tax repatriation rate. Applying statistical analysis, West and Schneider (2018) estimate that the most populous African countries of South Africa, Nigeria, Tanzania, Ethiopia, the Democratic Republic of the Congo, and Egypt would earn $\$ 2.2$ billion in revenues for HIV/AIDS treatments for the years 2017-2021. This estimate comes before the additional costs of breakage, marketing, transportation, and production. They further estimate that the Middle East and North Africa and Sub-Saharan Africa regions would earn $\$ 4.3$ billion, and that worldwide revenues could be as high as $\$ 6.1$ billion for the years 2017-2021. The various pharmaceutical companies may have more detailed information about drug development costs.

\section{A procedure for estimating the model parameters, with exemplification}

This section provides a procedure for determining and estimating the model's parameters, the strategic choices $X$ and $S$ by the donor, and the strategic choices $q, x, w$ by Nature, as expressed in the nomenclature in section "Nomenclature". The drug purchasing cost $C$ for person $i, i=1, \ldots, N$, was in section "Costs of HIV/AIDS treatment" estimated to be \$75-160 per year. As an intermediate example we choose $C=\$ 100$. The drug production cost $c$ for the pharmaceutical company destined for person $i$, $i=1, \ldots, N$, is lower than $C$. We choose $20 \%$ lower, which gives
$\$ 80$ per person per year. The exponential parameter $k$ scaling drug production cost depends on the possibility of economy of scale. For small markets and inefficient production it may be slightly less than linear, i.e. slightly below 1 . For larger markets and more efficient production, concavity becomes more prominent causing $k$ to be $<1$. We choose $k=0.5$. The drug development cost $d$ is in section "HIV R\&D costs and revenues" estimated to be $d=\$ 2.6$ billion.

Person $i$ 's utility $E_{i}$ of risky behavior, $i=1, \ldots, N$, can vary greatly between the $N$ persons. To attempt establishing an upper limit, we may estimate person $i$ 's utility $D_{i}$ of death, $D_{i}<R_{i}, i=1$, $\ldots, N$, by applying the common estimate of the value of statistical life, which Appelbaum (2011) estimates as \$6.1-\$9.1 million. ${ }^{3}$ To simplify the numbers we choose $D_{i}=-\$ 7$ million, where "-" means minus since the utility $D_{i}$ of death is negative. Person $i$ 's utility $E_{i}$ of risky behavior is presumably lower than the value of statistical life for most persons, since life consists of more than risky behavior. That is, most persons also receive utility from non-risky behavior, such as communication, relaxation, entertainment, eating, and sleeping. One possible estimate is that person $i$ 's utility $E_{i}$ of risky behavior is $1 / 7$ of the value of statistical life, i.e. $E_{i}=1$ million. Person $i$ 's utility $H_{i}$ of safe behavior, $H_{i}<E_{i}, i=1, \ldots, N$, is less than person is utility $E_{i}$ of risky behavior. One possible estimate is $H_{i}=0.5 E_{i}=\$ 0.5$ million. Person $i$ 's utility $R_{i}$ when recovering from disease, $R_{i}<H_{i}, i=1$, $\ldots, N$, is less than person $i$ 's utility $H_{i}$ of safe behavior. One possible estimate is $R_{i}=0.4 H_{i}=\$ 0.2$ million.

Assuming that the donor's two strategic choices are parametric, the subsidy fraction $X$ of drug development cost $d$ in period 3, and the subsidy fraction $S$ of drug purchasing cost $C$ for person $i$ in period 4, may partly be estimated from Table 4 which shows the total HIV resource availability in US\$ billion for low-income and middle-income countries 2000-2018. For example, the four percentages $56.04 \%, 8.41 \%, 27.02 \%$, and $8.52 \%$ in the bottom row for 2018, specify how domestic (public and private), global fund, United States (bilateral), and Other international, respectively, contribute resources for low-income and middle-income countries. Some of these funds may flow to the pharmaceutical company. The subsidy fraction $X$ of drug development cost $d$ is likely below 1 , since the company usually is profit-seeking and may be willing to incur costs to reap a benefit. The subsidy fraction $X$ may possibly range from 0 to 0.7 or 0.8 . We choose $X=0.5$. The

Table 4 Total HIV resource availability in US\$ billion for low- and middle-income countries 2000-2018.

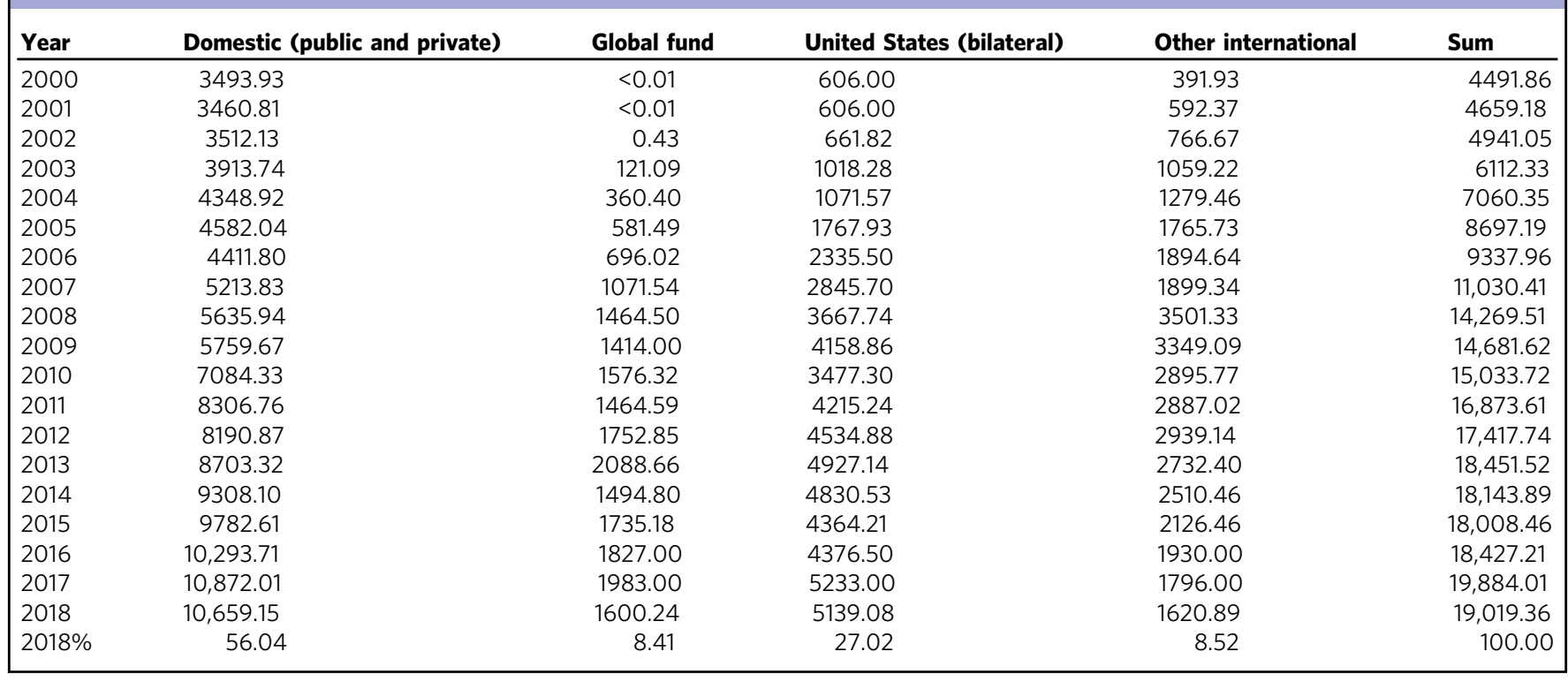




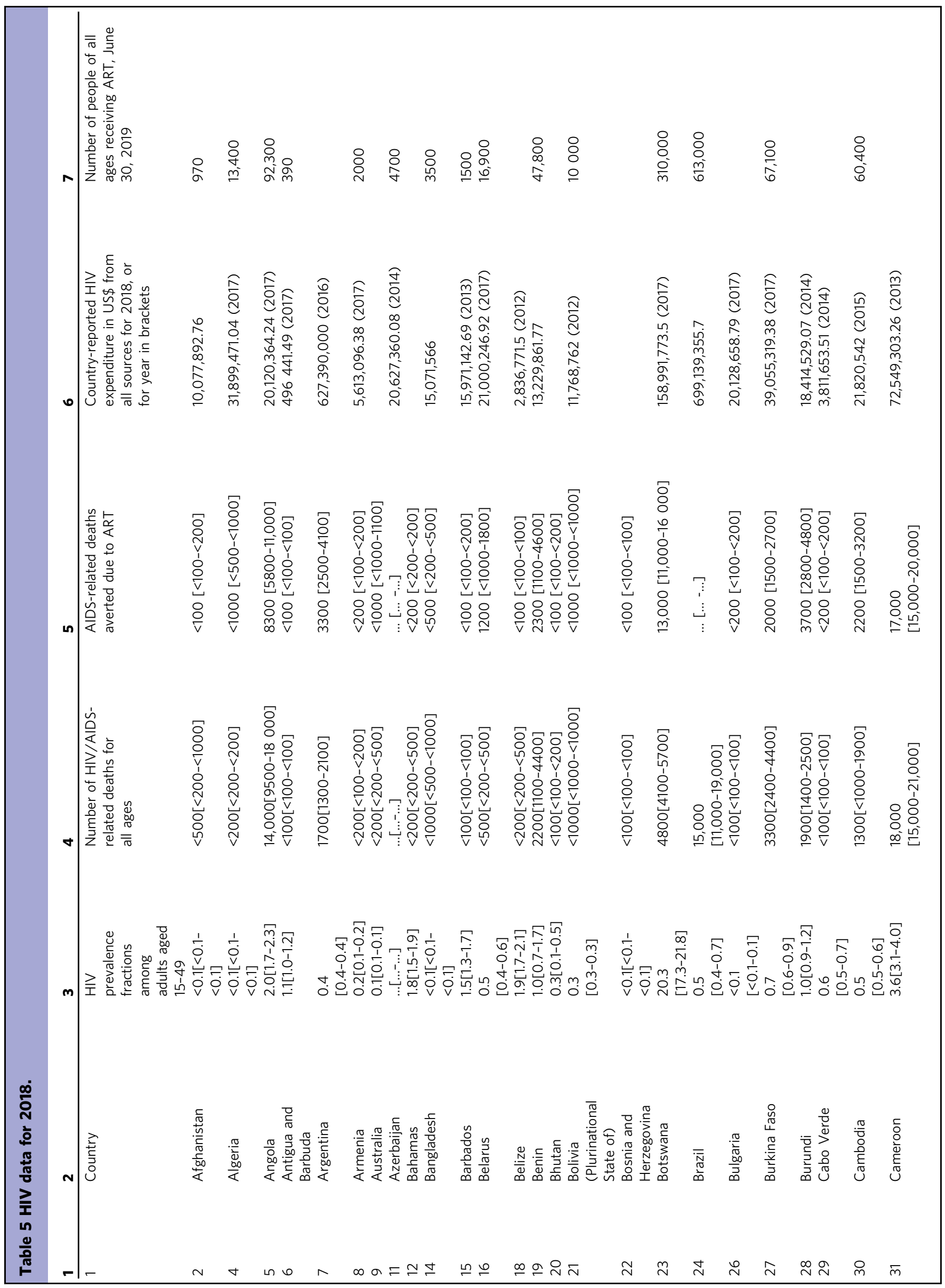




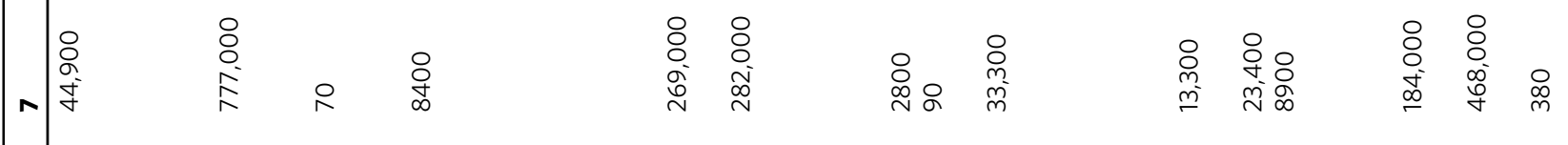

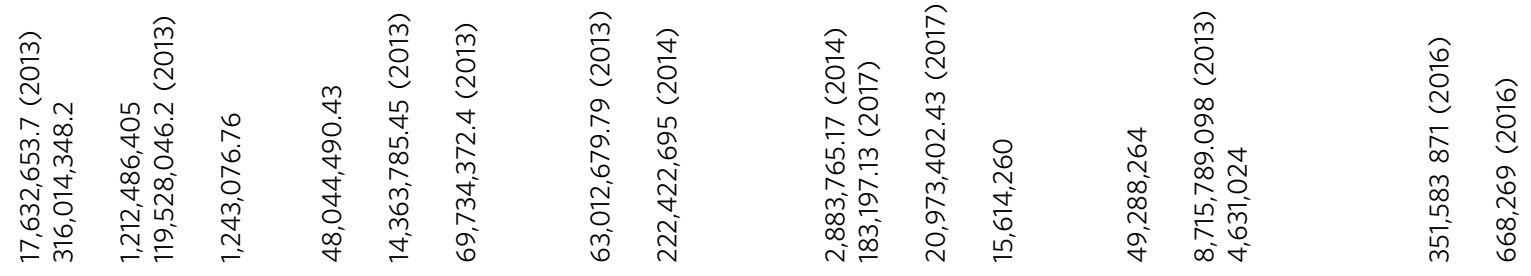

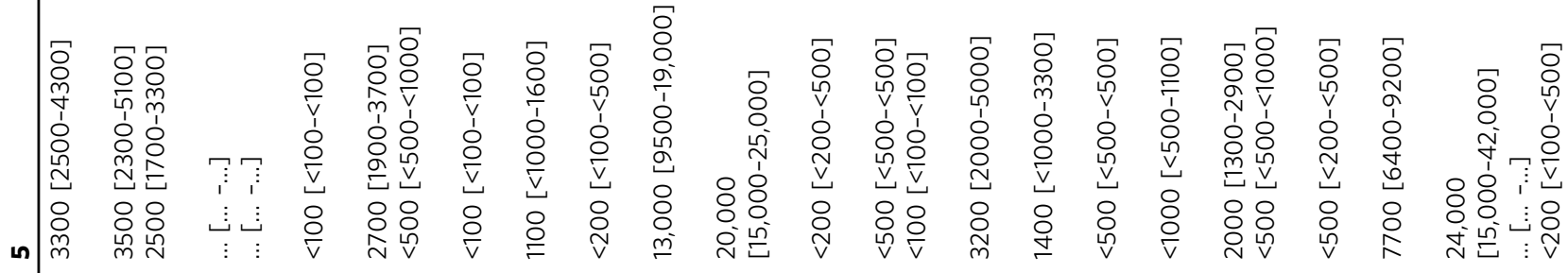

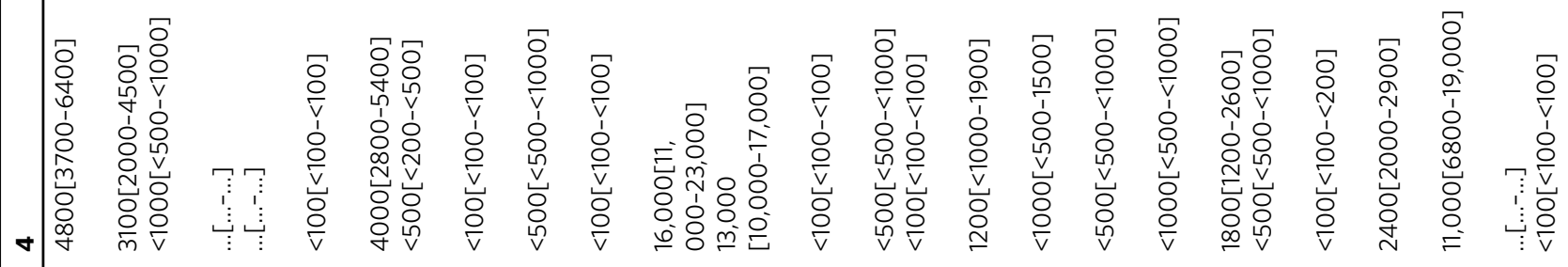

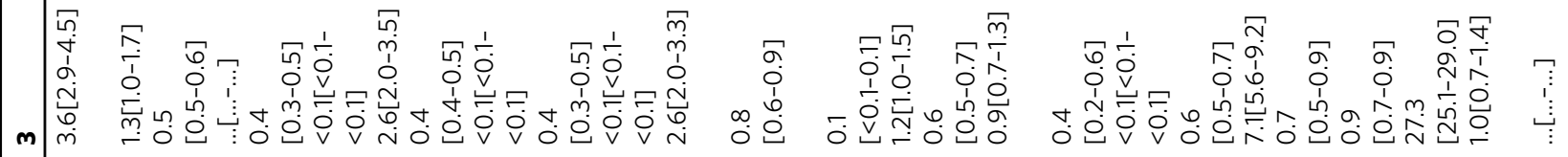

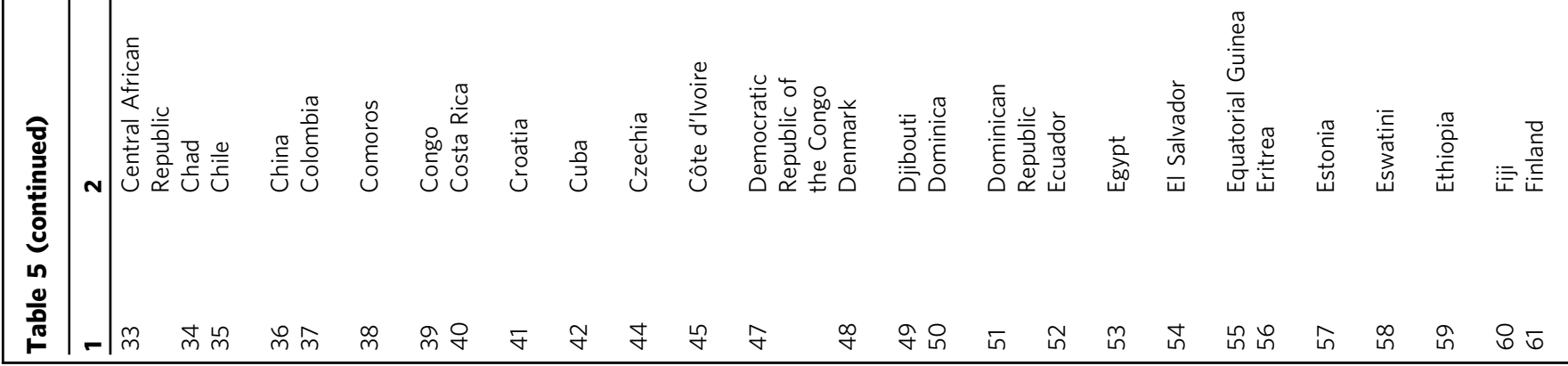




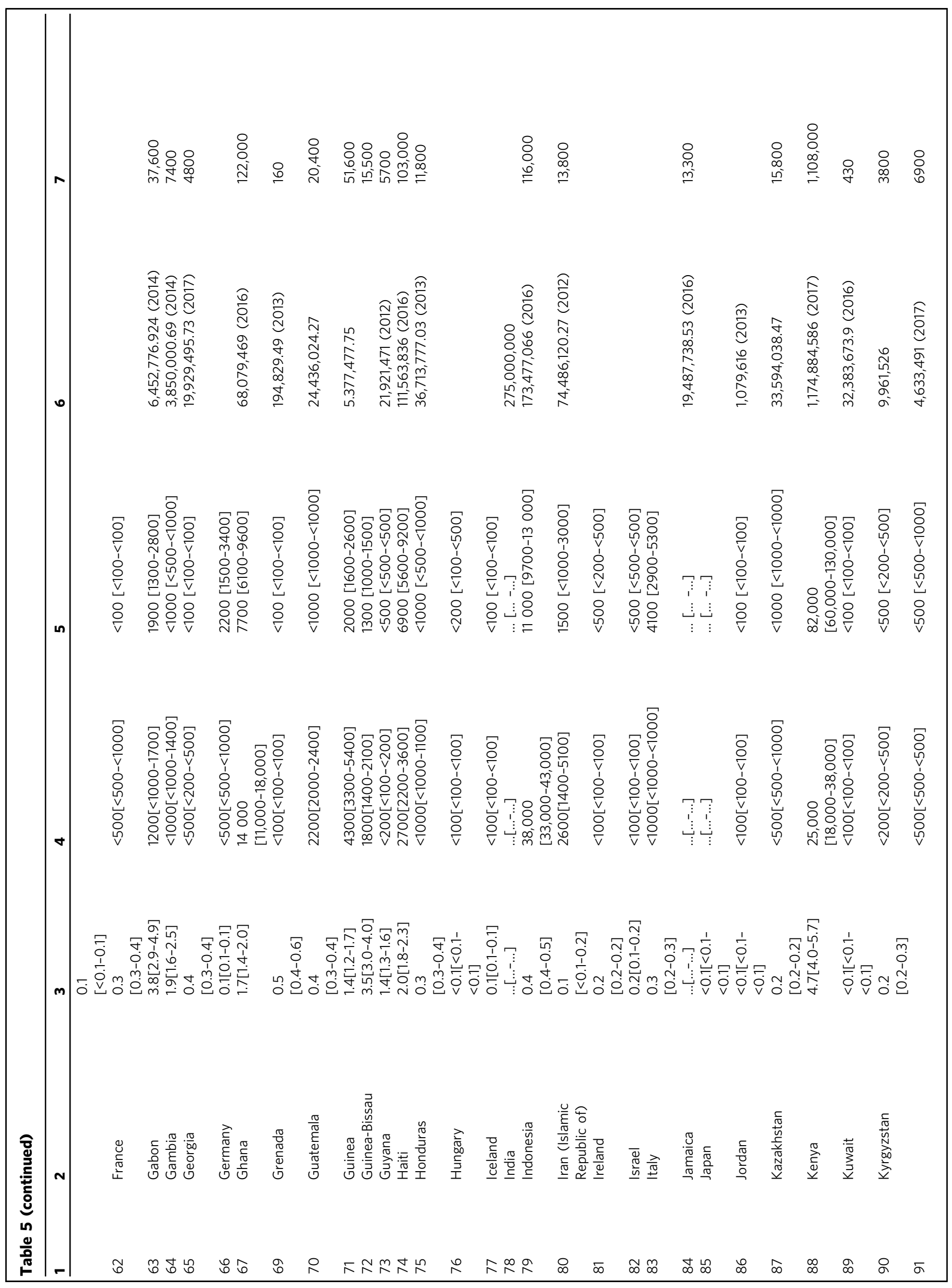




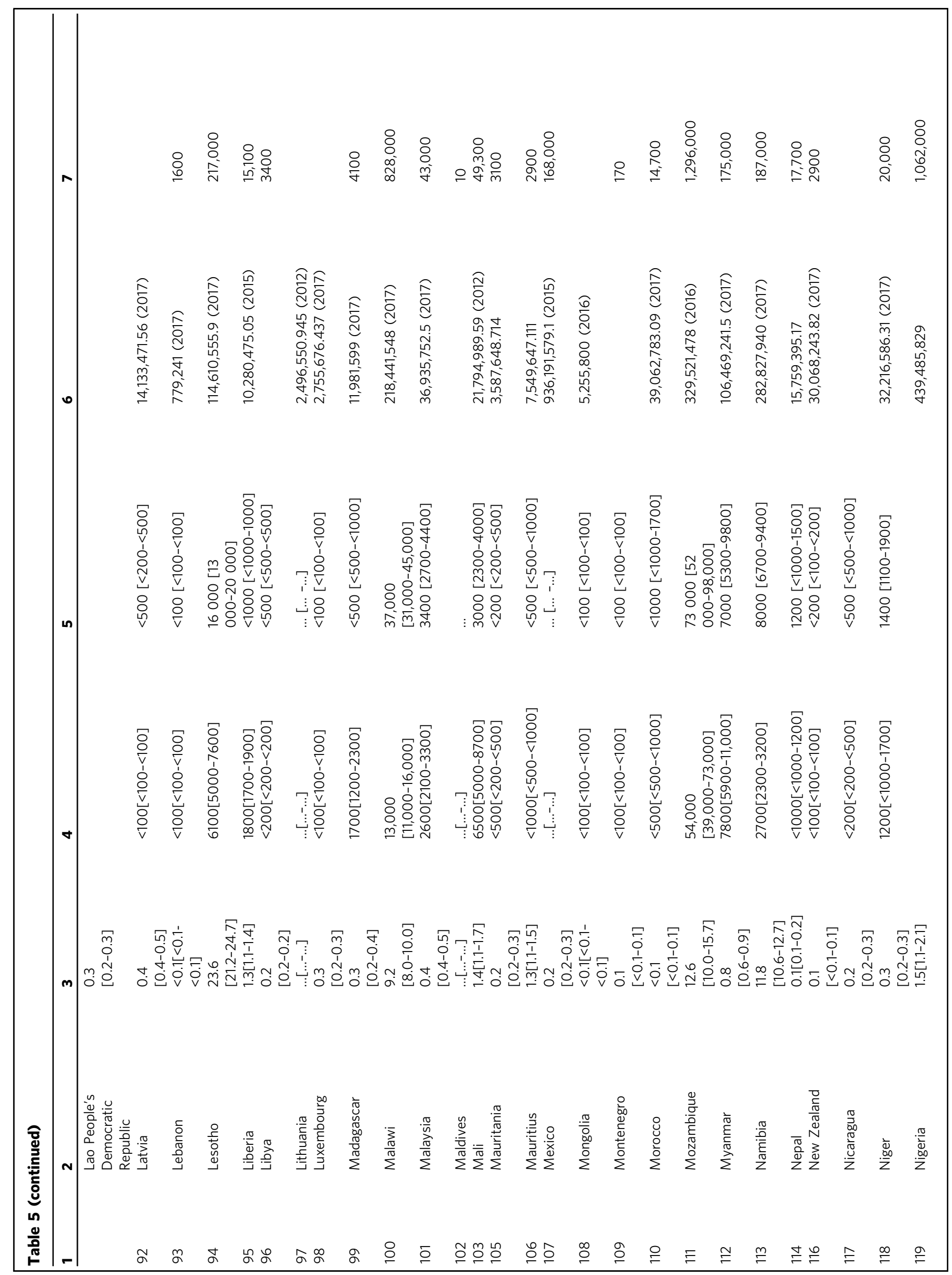




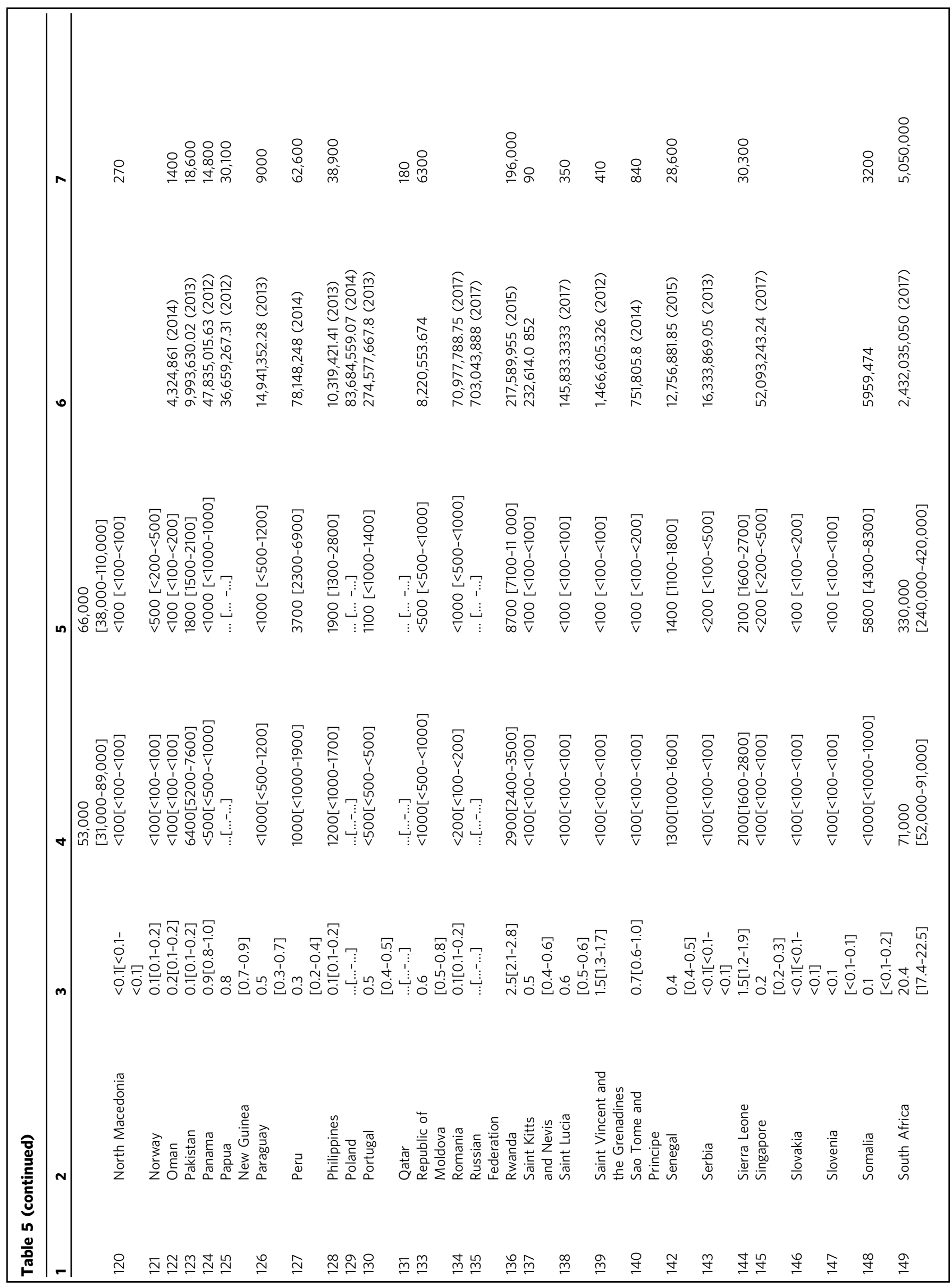




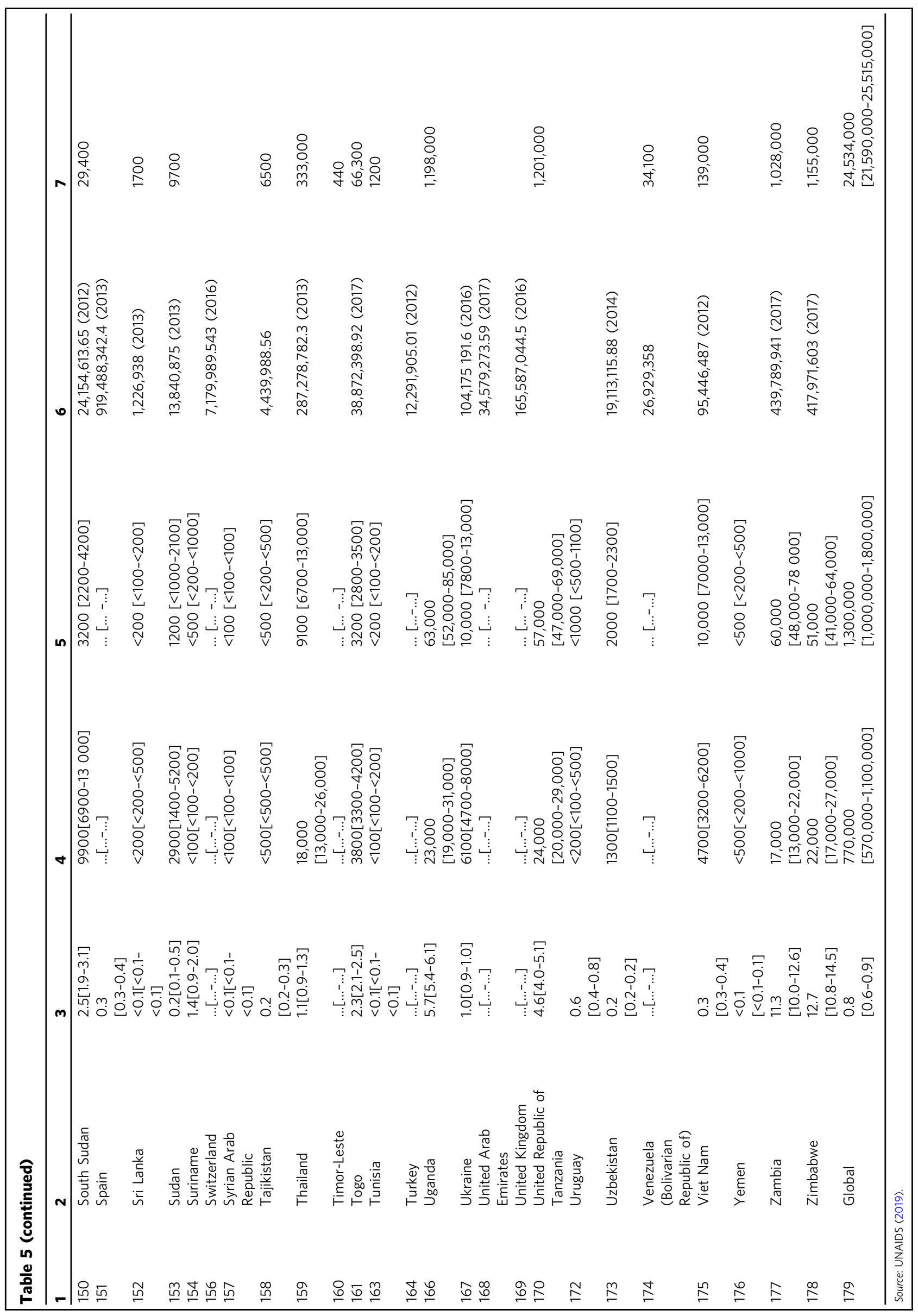


subsidy fraction $S$ of drug purchasing cost $C$ may also be impacted by the funds in Table 4. For some countries, e.g. countries with extensive social welfare or other arrangements, $100 \%$ subsidy may be possible. The opposite extreme, $0 \%$ subsidy also seems possible. Hence $S$ may range from 0 to 1 . We choose $S=0.5$.

Assuming that Nature's three strategic choices are parametric, the disease contraction probability $q$ in period 2 may be estimated by column 3 in Table 5, which provides the HIV prevalence \% among adults aged 15-49. Table 5 shows, from left to right, HIV prevalence \% among adults aged 15-49, Number of HIV/AIDSrelated deaths for all ages, AIDS-related deaths averted due to ART, Country-reported HIV expenditure in US\$ from all sources for 2018, or for year in brackets, and Number of people of all ages receiving ART, for 2018, except when otherwise specified. Although the global average is 0.008 , the distribution is strongly skewed. The numbers range from $<0.1$ (e.g. Afghanistan), via 0.204 for South Africa, to 0.273 for Eswatini. The disease contraction probability $q$ of risky behavior can be expected to be higher than the prevalence. To illustrate this, assume that risky behavior in interaction with an individual who has contracted the disease causes disease contraction with high probability close to one. With prevalence 0.204, such as in South Africa, random matching once means close to 0.204 probability of disease contraction. Repeated interaction increases the probability of disease contraction. Random matching may be an inappropriate assumption since individuals who have contracted the disease may abstain from interaction for moral or legal reasons. Nevertheless, it is quite possible that the disease contraction probability $q$ of sufficiently risky behavior may be high, and range from the prevalence probability in column 3 in Table 5, and up to one. In the example in the next section we assume $q=0.1$, which is higher than most prevalence fractions in Table 5, except for Africa. The disease recovery probability $x$ without the drug in periods 4 and/or 5 may be low for some diseases, and close to or equal to zero for the most serious diseases. One example is to assume $x=0.1$. The disease recovery probability $w$ with the drug in period 5 may be high for some diseases, and close to or equal to one for the most successful drugs. One example is to assume $w=0.9$.

The parameter values above, and assuming that $m=14$ million persons buy the drug, gives the inequalities in the rightmost column in Table 3. If the drug is not optimal for person $i$ to buy, or the drug is unavailable, person $i$ chooses safe behavior since $272,000<500,000$ violating Eq. (6), which gives outcome 1 . If person is utility $H_{i}=\$ 0.5$ million of safe behavior decreases below $H_{i}=\$ 0.272$ million, Eq. (6) is satisfied, and person $i$ chooses risky behavior instead. On the other hand, if the drug is available and optimal to buy for person $i$, it chooses risky behavior since $847,995>500,000$ according to Eq. (7), which gives outcome 2 if the disease is not contracted. If person $i$ 's utility $H_{i}$ $=\$ 0.5$ million of safe behavior increases above $H_{i}=\$ 0.847995$ million, Eq. (7) is not satisfied, and person $i$ chooses safe behavior instead. If person $i$ chooses risky behavior, and the disease is contracted, outcomes 1 and 2 are impossible, and hence outcomes 3,4 , or 5 occurs instead. Outcomes 3 and 4 are excluded since Eq. (6) is not satisfied, since $272,000<500,000$. That is, drug unavailability or not buying the drug are excluded. In contrast, outcome 5 arises since the drug is available, and is optimal for person $i$ to buy. Thus the bottom row in Table 3 specifies Yes to three conditions. First, Eq. (4) is satisfied so that person $i$ buys the drug since the benefits outweigh those of not buying the drug. Second, Eq. (5) is satisfied so that the pharmaceutical company develops the drug, which it does if at least $m=14$ million persons buy the drug. With fewer than $m=14$ million persons buying the drug, the pharmaceutical company does not develop it. Then the drug is unavailable, causing person $i$ to choose safe behavior with the current parameter values. Third, Eq. (7) is satisfied so that that person $i$ buys the drug since the benefits of risky behavior combined with buying the drug outweighs the utility of safe behavior. Inserting the parameter values into Eq. (1), person $i$ 's utility is

$U_{i}=\left\{\begin{array}{l}\$ 500,000 \text { if safe behavior } \\ \$ 1,000,000 \text { if risky behavior and no disease contraction } \\ -\$ 6.28 \times 10^{6} \text { if risky behavior \& disease contraction \& no drug development } \\ -\$ 6.28 \times 10^{6} \text { if risky behavior \& disease contraction \& drug development\&not buy drug } \\ -\$ 520,050 \text { if risky behavior \& disease contraction \& drug development \& buy drug. }\end{array}\right.$

Equation (9) shows that outcome 2 (line 2) occurs if the disease is not contracted, while outcome 5 (line 5) occurs if the disease is contracted. Hence the drug availability induces risky behavior with these parameter values. Inserting the parameter values into Eq. (2), the pharmaceutical company's profit is

$$
u=\left\{\begin{array}{l}
0 \text { if no drug development } \\
\$ 9.99665 \times 10^{7} \text { if drug development }
\end{array}\right.
$$

and hence the pharmaceutical company prefers to develop the drug. To determine the donor's utility, the four additional parameters $N, G, L, M$ must be estimated. The number $N$ of persons is determined from population statistics databases for the group one seeks to study, e.g. a country in Table 5 . We choose $N=100$ million. The number $G$ of persons choosing safe behavior is obviously less than $N$, and may be assessed by indicators of safe behavior such as buying condoms for sexually transmitted diseases. We choose $G=40$ million. The number $L$ of persons choosing risky behavior while not contracting the disease is challenging to assess. It is obviously less than $N-G$. We choose $L=30$ million. The number of $m$ of persons buying the drug is obviously less than $N-G-L$, since a person cannot be expected to buy the drug if not contracting the disease. Above we chose $m=14$ million. The number $M$ of persons not buying the drug despite drug production by the pharmaceutical company is obviously less than $N-G-L-m$. We choose $M=10$ million. The above estimates enable estimating $N-G-L-M-m=6$ million which, as stated in section "Pharmaceutical company's behavior, benefits, and costs", is the unfortunate number of persons which contracts the disease without drug availability (since the pharmaceutical company does not develop it). We assume that all persons are equivalent to person $i$. Inserting these parameter values into Eq. (3), the donor's utility is

$$
V=\left\{\begin{array}{l}
-\$ 1.384 \times 10^{14} \text { and } M=m=0 \text { if no drug development } \\
-\$ 5.7762 \times 10^{13} \text { if drug development. }
\end{array}\right.
$$

Hence the donor prefers drug development, to obtain the higher utility in Eq. (11). Line 1 in Eq. (11) specifies lower (more negative) utility to person $i$ due to the third sum in Eq. (3), which sums the negative utility $(1-x) D_{i}+x R_{i}$ for person $i$ over $N-G-L$ persons, instead of summing over $N-M-m-G-L$ persons as in line 2. The fourth sum in line 2 in Eq. (3) also sums the negative utility $(1-x) D_{i}+x R_{i}$ for person $i$, over $M$ persons who do not buy the drug. However, the fifth sum in line 3 in Eq. (3) sums the utility $(1-w) D_{i}+w R_{i}$ for person $i$, which is higher than $(1-x) D_{i}+x R_{i}$ since $x \leq w$, over $m$ persons who buy the drug. When $m$ is sufficiently high, that causes line 2 in Eq. (11) to be higher than line 1. That both lines in Eq. (11) are negative is sometimes characteristic of a donor which may be due to factors not modeled in this article. Examples of such factors are charitable contributions, or aid from governments or public or private enterprises seeking economic prosperity potentially arising from a more healthy labor force. 


\section{Discussion of results, limitations, and future research}

The usefulness of the model lies in identifying the strategic interaction between $N$ persons choosing risky versus safe behavior, and a pharmaceutical company choosing whether or not to develop a drug, with further impact by a donor and Nature. This strategic interaction has five outcomes, i.e. person $i$ prefers safe behavior, no disease contraction causing risky behavior, contracting the disease without drug availability, contracting the disease with drug availability but without buying the drug, and contracting the disease with drug availability and buying the drug. The estimation of parameters in section "A procedure for estimating the model parameters, with exemplification" illustrates how each of these five outcomes can be realized. In particular, one specific choice of parameters is illustrated as an example which gives the fifth outcome in the top right corner of the game tree in Fig. 1. As the world changes, each of these parameters may change which of the five outcomes occurs, enhancing our understanding of the phenomenon. For example, technological developments may enable more effective drugs which may potentially be cheaper, and produced more effectively, which may impact the players' strategic choices. Societal changes in preferences, beliefs, demography and modes of interaction may change the persons' utilities of the various outcomes, and cause changed probabilities of disease contraction, recovery, and death. Understanding the impact of such changes may enable not only the players to choose better strategies, but may also enable policy makers and other external players not modeled in this article, but which may be modeled in the future, to make wise decisions.

Limitations of the article pertain to the challenges of modeling a complex phenomenon involving choices of persons, a pharmaceutical company, and donors over time. Further challenges pertain to Nature choosing disease contraction, recovery, and death; technological and competence conditions regarding drug development, and market conditions regarding pricing of drugs and drug development. Some of these limitations can be addressed as follows in future research.

Future research may assess how the model, and especially recovery from disease (which may cause healthier people and increase life expectancy) weighed against drug availability and costs, impacts a country's economy, productivity, income earnings, and economic growth. Research may distinguish between different kinds of people (according to age, sex, occupation, ethnicity/race, etc.), and consider various distributions of different types of persons regarding their utilities for risky behavior, safe behavior, recovery from disease, and death. Research may model more than one pharmaceutical company, enable strategic choices by more than one donor, and incorporate more choices by Nature. Future research may also model a variety of different players such as doctors, hospitals, regulators, and politicians.

Future research may model the donor as a strategic player sponsoring drug development and drug purchases, and may endogenize Nature's parametric choices. The disease contraction probability may for infectious diseases be assumed to depend on the number of persons having previously contracted the disease in the setting where a given person operates (cf. the discussion about random matching in the previous section). The disease recovery probability without and with the drug may be endogenized by modeling the biological process by which viruses evolve (Moxnes and Hausken, 2012; Sun et al., 2020).

Models may also be developed where people choose risky versus safe behavior at different stages of drug development, i.e. at early stages with tentative or explorative drugs versus mature stages when drugs have proven their effectiveness over time. Models may also be developed to incorporate different expectations by the players regarding whether a drug will be available in the future. Future research may also develop more specific models adjusted to the specifics of various diseases. Future research should compile empirical data on other diseases than HIV/AIDS to assess compatibility with the model.

\section{Conclusion}

The article develops a five-period game between $N$ persons and a pharmaceutical company. Each person chooses between risky and safe behavior which may cause disease, such as Covid-19 infection or HIV/AIDS. If contracting the disease, each person additionally chooses whether or not to buy a drug. The pharmaceutical company develops the drug if sufficiently many persons contract the disease and are willing to buy the drug. The donor chooses parametrically whether to subsidize drug development and drug purchases, which impacts whether the pharmaceutical company develops the drug and persons contracting the disease buy it. Nature chooses probabilistically whether a person with risky behavior contracts the disease, and whether the person recovers or dies under three circumstances. These are no drug availability, drug availability without buying the drug, and buying and using the drug.

Five outcomes determine each person's utility, depending on safe behavior, risky behavior without disease contraction, risky behavior with disease contraction and no drug availability, drug availability without buying the drug, and buying the drug. Two outcomes determine the pharmaceutical company's profit, depending on no drug development (outcomes 1-3 for the persons), and drug development (outcomes 4 and 5 for the persons). These two outcomes also determine the donor's utility.

The game is solved with backward induction specifying the conditions for each of the five outcomes. The conditions are specified as inequalities for the parameters. A procedure for estimating the parameters is provided, based on HIV/AIDS data for prevalence, deaths, HIV expenditure, treatment costs, R\&D costs and revenues, and HIV resource availability, for various countries. An example illustrates how a person decides between risky and safe behavior, and between buying and not buying the drug, how the pharmaceutical company decides between developing or not developing the drug, and how the donor's utility is impacted. The model is provided as a tool to understand persons' behavior regarding contracting disease and purchasing drugs when interacting with a pharmaceutical company which may or may not develop drugs, a donor which may or may not subsidize, and Nature which may precariously determine disease contraction, recovery, and death.

\section{Data availability}

All data generated or analyzed during this study is included in this published article.

Received: 23 February 2020; Accepted: 8 October 2020;

Published online: 12 November 2020

\section{Notes}

1 https://www.amfar.org/About-HIV-and-AIDS/Basic-Facts-About-HIV/, retrieved October 23, 2020

2 https://www.kcbd.com/2020/03/16/live-coronavirus-covid-global-cases-map/, retrieved October 23, 2020.

3 Such valuations usually follow from weighing wages against death risk in the labor market, or more generally on how persons strike balances between health risks and rewards.

\section{References}

Alistar SS, Brandeau ML (2012) Decision making for HIV prevention and treatment scale up: bridging the gap between theory and practice. Med Decis Mak 32(1):105-117. https://doi.org/10.1177/0272989x10391808 
Appelbaum B (2011). As U.S. Agencies put more value on a life, businesses fret. N Y Times. http://www.nytimes.com/2011/02/17/business/economy/17regulation.html Bärnighausen T, Salomon JA, Sangrujee N (2012). HIV treatment as prevention: issues in economic evaluation. PLoS Med https://doi.org/10.1371/journal. pmed.1001263

Bertozzi S, Padian NS, Wegbreit J, DeMaria LM, Feldman B, Gayle H, Gold J, Grant R, Isbell MT (2006) HIV/AIDS prevention and treatment. In: Jamison DT, Breman JG, Measham AR, Alleyne G, Claeson M, Evans DB, Jha P, Mills A, Musgrove P (eds) Disease control priorities in developing countries, 2nd edn. The International Bank for Reconstruction and Development/The World Bank, Washington, pp. 331-370.

Boily M-C, Mâsse B, Alsallaq R, Padian NS, Eaton JW, Vesga JF, Bartlett J (2012) HIV treatment as prevention: considerations in the design, conduct, and analysis of cluster randomized controlled trials of combination HIV prevention. PLoS Med 9(7):e1001250. https://doi.org/10.1371/journal.pmed.1001250

Canning D (2006) The economics of HIV/AIDS in low-income countries: the case for prevention. J Econ Perspect 20(3):121-142. https://doi.org/10.1257/jep.20.3.121

Clinton Health Access Initiative (2018). Annual report 2018. http://clintonhealthaccess. org/wp-content/uploads/2019/12/CHAI-ANNUAL-REPORT.pdf

Coates TJ, Richter L, Caceres C (2008) Behavioural strategies to reduce HIV transmission: how to make them work better. Lancet 372(9639):669-684. https://doi.org/10.1016/S0140-6736(08)60886-7

Cohen D, Shin-Yi W, Farley T (2005) Cost-effective allocation of government funds to prevent HIV infection. Health Aff 24(4):915-926

Creese A, Floyd K, Alban A, Guinness L (2002) Cost-effectiveness of HIV/AIDS interventions in Africa: a systematic review of the evidence. Lancet 359 (9318):1635-1642. https://doi.org/10.1016/S0140-6736(02)08595-1

DiMasi JA, Grabowski HG, Hansen RW (2016) Innovation in the pharmaceutical industry: new estimates of R\&D costs. J Health Econ 47:20-33. https://doi. org/10.1016/j.jhealeco.2016.01.012

Fitzpatrick MC, Singer BH, Hotez PJ, Galvani AP (2017) Saving lives efficiently across sectors: the need for a congressional cost-effectiveness committee. Lancet https://doi.org/10.1016/S0140-6736(17)31440-X

Forsythe SS, McGreevey W, Whiteside A, Shah M, Cohen J, Hecht R, Kinghorn A (2019) Twenty years of antiretroviral therapy for people living with HIV: global costs, health achievements, economic benefits. Health Aff 38(7):1163-1172

Galárraga O, Colchero MA, Wamai RG, Bertozzi SM (2009) HIV prevention costeffectiveness: a systematic review. BMC Public Health 9(Suppl 1):S5-S5. https://doi.org/10.1186/1471-2458-9-S1-S5

Goldie SJ, Yazdanpanah Y, Losina E, Weinstein MC, Anglaret X, Walensky RP, Freedberg KA (2006) Cost-effectiveness of HIV treatment in resource-poor settings-the case of Côte d'Ivoire. New Eng J Med 355(11):1141-1153. https://doi.org/10.1056/NEJMsa060247

Gonsalves G (2002) HIV/AIDS prevention and treatment. Lancet 360(9326):87-87. https://doi.org/10.1016/S0140-6736(02)09344-3

Granich R, Kahn JG, Bennett R, Holmes CB, Garg N, Serenata C, Zhang C (2012) Expanding ART for treatment and prevention of HIV in South Africa: estimated cost and cost-effectiveness 2011-2050 (expanding ART for HIV treatment and prevention). PLoS ONE 7(2):e30216. https://doi.org/10.1371/ journal.pone.0030216

Hausken K, Ncube M (2017) Policy makers, the international community and the population in the prevention and treatment of diseases: case study on HIV/ AIDS. Health Econ Rev 7(1):1-12. https://doi.org/10.1186/s13561-016-0139-x

Hausken K, Ncube M (2018) Policy makers, the international community and people living with HIV/AIDS: the need for new commitment mechanisms. Int J Public Policy 14(3/4):275-301

Hecht R, Stover J, Bollinger L, Muhib F, Case K, de Ferranti D (2010) Financing of HIV/AIDS programme scale-up in low-income and middle-income countries, 2009-31. Lancet 376(9748):1254-1260. https://doi.org/10.1016/S01406736(10)61255-X

HIV Modelling Consortium Treatment as Prevention Editorial Writing Group (2012) HIV treatment as prevention: models, data, and questions-towards evidence-based decision-making. PLoS Med 9(7):e1001259. https://doi.org/ 10.1371/journal.pmed.1001259

Hogan DR, Baltussen R, Hayashi C, Lauer JA, Salomon JA (2005) Cost effectiveness analysis of strategies to combat HIV/AIDS in developing countries. BMJ 331(7530):1431. https://doi.org/10.1136/bmj.38643.368692.68

Izazola-Licea JA, Wiegelmann J, Arán C, Guthrie T, De Lay P, Avila-Figueroa C (2009) Financing the response to HIV in low-income and middle-income countries. J Acquir Immune Defic Syndr 52:S119-S126

Kremer M, Glennerster R (2004) Strong medicine: creating incentives for pharmaceutical research on neglected diseases. Princeton University Press, Princeton

Kremer M, Snyder CM (2003) Why are drugs more profitable than vaccines? Vol. 9833. National Bureau of Economic Research, Cambridge
Kremer M, Snyder CM (2015) Preventatives versus treatments. Department of Economics, Harvard University.

Kumaranayake L, Watts C, Dixon S, Mc Donald S, Roberts J (2001) Resource allocation and priority setting of HIV/AIDS interventions: addressing the generalized epidemic in sub-Saharan Africa. J Int Dev 13(4):451-466. https:// doi.org/10.1002/jid.797

Lansdowne LE (2020). Exploring the drug development process. https://www. technologynetworks.com/drug-discovery/articles/exploring-the-drugdevelopment-process-331894

Mamani H, Chick SE, Simchi-Levi D (2013) A game-theoretic model of international influenza vaccination coordination. Manag Sci 59(7):1650-1670

Médecins Sans Frontières. (2020). Access to medicines: medicines shouldn't be a luxury. https://www.msf.org/access-medicines-depth

Moxnes JF, Hausken K (2012) Mathematical modelling of acute virus influenza A infections. Math Comput Model Dyn Syst 18(5):521-538

Paltiel AD, Stinnett AA (1998) Resource allocation and the funding of HIV prevention. In: Holtgrave DR (ed.), Handbook of economic evaluation of HIV prevention programs. Springer, pp. 135-152.

Pillai N, Foster N, Hanifa Y, Ndlovu N, Fielding K, Churchyard G, Vassall A (2019) Patient costs incurred by people living with HIV/AIDS prior to ART initiation in primary healthcare facilities in Gauteng, South Africa. PLoS ONE 14(2):e0210622. https://doi.org/10.1371/journal.pone.0210622

Sun J, He W-T, Wang L, Lai A, Ji X, Zhai X, Su S (2020) COVID-19: epidemiology, evolution, and cross-disciplinary perspectives. Trends Mol Med 26 (5):483-495. https://doi.org/10.1016/j.molmed.2020.02.008

Thomas P (2001) Big shot: passion, politics, and the struggle for an AIDS vaccine. Public Affairs, New York

UNAIDS (2019) AIDSinfo. http://aidsinfo.unaids.org/

Walker D (2003) Cost and cost-effectiveness of HIV/AIDS prevention strategies in developing countries: is there an evidence base? Health Policy Plan 18 (1):4-17

West DM, Schneider J (2018) Measuring revenue streams and profitability for hiv drugs. https://www.brookings.edu/research/measuring-revenue-streams-andprofitability-for-hiv-drugs/

World Bank (2019) New country classifications by income level: 2019-2020. http:// blogs.worldbank.org/opendata/new-country-classifications-income-level2019-2020

World Health Organization (2020) Global price reporting mechanism for HIV, tuberculosis and malaria. https://www.who.int/hiv/amds/gprm/en/

\section{Funding}

Open Access funding enabled and organized by Projekt DEAL.

\section{Competing interests}

The authors declare no competing interests.

\section{Additional information}

Correspondence and requests for materials should be addressed to K.H.

Reprints and permission information is available at http://www.nature.com/reprints

Publisher's note Springer Nature remains neutral with regard to jurisdictional claims in published maps and institutional affiliations.

Open Access This article is licensed under a Creative Commons Attribution 4.0 International License, which permits use, sharing, adaptation, distribution and reproduction in any medium or format, as long as you give appropriate credit to the original author(s) and the source, provide a link to the Creative Commons license, and indicate if changes were made. The images or other third party material in this article are included in the article's Creative Commons license, unles indicated otherwise in a credit line to the material. If material is not included in the article's Creative Commons license and your intended use is not permitted by statutory regulation or exceeds the permitted use, you will need to obtain permission directly from the copyright holder. To view a copy of this license, visit http://creativecommons.org/ licenses/by/4.0/

(C) The Author(s) 2020 